\title{
Do Individual Characteristics Influence the Types of Technostress Reported by Workers?
}

\section{Danilo Magno Marchiori, Emerson Wagner Mainardes \& Ricardo Gouveia Rodrigues}

To cite this article: Danilo Magno Marchiori, Emerson Wagner Mainardes \& Ricardo Gouveia Rodrigues (2018): Do Individual Characteristics Influence the Types of Technostress Reported by Workers?, International Journal of Human-Computer Interaction, DOI: 10.1080/10447318.2018.1449713

To link to this article: https://doi.org/10.1080/10447318.2018.1449713

曲 Published online: 22 Mar 2018.

Submit your article to this journal $\sqsubset$

Q View related articles $\longleftarrow$

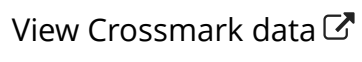




\title{
Do Individual Characteristics Influence the Types of Technostress Reported by Workers?
}

\author{
Danilo Magno Marchiori $\mathbb{1}^{\mathrm{a}}$, Emerson Wagner Mainardes ${ }^{\mathrm{b}}$, and Ricardo Gouveia Rodrigues $\mathbb{0}^{\mathrm{c}}$ \\ aDepartamento de Gestão e Economia, Universidade da Beira Interior, Covilhã, Portugal; bAdministration Department, FUCAPE Business School, \\ Vitória, Brazil; 'Department of Management and Economics, Universidade da Beira Interior, Covilhã, Portugal
}

\begin{abstract}
Based on the perspective that the diversity of the workforce has implications for attitudes and behaviors at the individual and group levels, this article examines the role of individual differences related to gender, age, formal education, and length of professional experience in the levels of stress caused by the use of information technology (IT) in the daily activities of workers. This phenomenon, termed in the literature as technostress, is studied by identifying and measuring the factors that create technostress (the technostress creator factors: techno-uncertainty, techno-invasion, techno-overload, and technocomplexity). The technostress phenomenon is related to the most varied types of disorders in workers and losses in organizations, such as fatigue, dissatisfaction, anxiety, and reduced productivity. To achieve the goal of this research, we applied structural equation models in a sample of 927 questionnaires completed by 14 different Brazilian public institutions that were distributed among all regions of the country and that were strongly dependent on IT for their main business processes. The results indicate that workers' demographic characteristics relate to one another differently and specifically with the various forms of manifestation of technostress. More precisely, older workers or those with longer professional experience reported greater difficulties with the increase of technological complexity for the execution of tasks (techno-complexity). Women reported being subject to higher levels of technocomplexity and techno-uncertainty, while men indicated feeling greater effects from techno-overload and techno-invasion. We did not detect differences related to the levels of formal education of workers. This study presents the implications of the results for theory and for the everyday life of modern organizations that are increasingly dependent on the use of IT.
\end{abstract}

\section{KEYWORDS}

Technostress; Individual Differences; Diversity; Structural Equation Models; MIMIC

\section{Introduction}

Currently, public and private organizations are expanding the use of information technology (IT) in their business processes (De Haes, Van Grembergen, \& Debreceny, 2013; Garicano \& Heaton, 2010). However, this technological expansion is accompanied by difficulties in adapting workers to the environment and the technological resources that they use. This problem, known as technostress, can have serious negative consequences for workers and organizations, such as reduced productivity and dissatisfaction with work (Tarafdar, $\mathrm{Tu}$, Ragu-Nathan, \& Ragu-Nathan, 2007). In decomposing the phenomenon, the literature that explores this theme explains that technostress is formed by five elements: techno-overload, techno-invasion, techno-insecurity, techno-complexity, and techno-uncertainty (Ragu-Nathan, Tarafdar, Ragu-Nathan, \& $\mathrm{Tu}, 2008$; Tarafdar et al., 2007).

In parallel, managers and researchers in the field of applied psychology are increasingly dedicated to studying the diversity of the workforce and trying to understand its consequences for organizations and workers (Joshi \& Roh, 2009; Lau \& Murnighan, 1998; Roberson, Ryan, \& Ragins, 2017; Williams \& O'Reilly III, 1998). Diversity refers to the existence of differences between individuals, in any attribute, allowing the definition of a large number of analyzable dimensions. However, according to Van Knippenberg, De Dreu, and Homan (2004), the literature on this field generally focuses on the analysis of differences related to gender, age, race (or ethnicity), ownership, and professional and educational background. In this regard and as stressed by Roberson et al. (2017), a large number of studies in the field of applied psychology evince the role of workforce diversity in the variations in attitudes and individual and group behaviors in organizations.

The IT literature is also rich in research that finds evidence that the demographic characteristics of users can influence the most diverse aspects of the acceptance and outcome of IT use in organizations (Çoklar \& Şahin, 2011; Fuglseth \& Sørebø, 2014; He \& Freeman, 2010; Venkatesh et al., 2003; Venkatesh \& Morris, 2000). In this connection, Zeithaml, Parasuraman, and Malhotra (2002) indicated the need for research that seeks to identify how individual responses to the use of IT can be influenced by users' individual characteristics. However, we did not find studies that specifically adjusted the focus of the research and deepened the investigation of the role of demographic variables in the factors that created 
technostress, despite the recent proliferation of studies addressing this theme (Ahmad, Amin, \& Wan Ismail, 2014; Ayyagari, Grover, \& Purvis, 2011; Fuglseth \& Sørebø, 2014; Jena \& Mahanti, 2014; Krishnan, 2017; Lee, Lee, \& Suh, 2016; Maier, 2014; Maier, Laumer, \& Eckhardt, 2015; Ragu-Nathan et al., 2008; Riedl, 2012; Tams, Hill, \& Thatcher, 2014; Tarafdar, Tu, \& Ragu-Nathan, 2010; Tarafdar et al., 2007; Yan, Guo, Lee, \& Vogel, 2013).

When it is studied, the relationship between the differences in individual users and technostress is only tangential in the area's research, and contradictory results are obtained. In addition to this connection, the knowledge gap that motivated the realization of the present study was the need to relate the demographic variables specifically to the technostress creator factors. Thus, in the present investigation, we seek to find the answer to the following question: do the individual differences in gender, age, educational level, and length of professional experience indicate the existence of statistically relevant differences in relation to technostress? In this regard, the objective of this study was to detect whether personal characteristics related to gender, age, educational level, and length of professional experience influence the manner in which they are impacted by technostress by analysis of the technostress creator factors.

Theoretical and practical reasons justify the realization of this research effort. We used structural equations to detect how groups of workers, segmented from the most common demographic characteristics in studies on diversity (Van Knippenberg et al., 2004), suffer from the use of technology in the workplace. That is, understanding the role of individual differences in the context of technostress, subdivided by the technostress creator factors, can provide IT managers with information that can contribute to the adoption of actions to counter the problem that are designed specifically for each audience. In addition, this information can serve as a basis for the training of technical staff in IT departments, with a focus on understanding the reactions and needs of each subset of users, segmented by gender, age, level of formal education, and length of professional experience. In the academic field of IT, understanding the role of individual differences in technostress, examined specifically in the context of each factor creating the phenomenon, can help us understand the seemingly contradictory results observed in previous research. Moreover, understanding the dynamics of the relationship between the individual characteristics and the factors that create technostress can provide insights for the analysis of other phenomena present in the IT literature.

\section{Literature review}

\subsection{Technostress creator factors}

The expansion of technology use in organizations is accompanied by reports of difficulties in adapting to technology presented by workers who use IT in their work activities (Tarafdar et al., 2007). This phenomenon is known in the literature as technostress, and its concept was presented for the first time in the early 1980s (Brod, 1984). Subsequently, in 1997, technostress was conceptualized as being "any negative impact on attitudes, thoughts, behaviors or physiology caused directly or indirectly by the use of technology" (Weil \& Rosen, 1997, p.5). Currently, there is evidence that relates the difficulty of adapting workers to the use of IT in organizational environments to reduced productivity and problems related to anxiety and worker fatigue (Tarafdar et al., 2010, 2007).

According to Riedl (2012), a central work in the literature on technostress is the study by Ayyagari et al. (2011), in which specific characteristics of technology (usability, intrusiveness, and dynamism) are investigated in regard to whether they influence IT-related stressors, more precisely, work overload, role ambiguity, job insecurity, work-home conflict, and invasion of privacy. The authors found evidence pointing to the influence of technological characteristics on the studied stressors and their effect on the respondents. Following this line, several studies find significant relationships between technostress and various aspects within the organizational and individual scope. For example, individual productivity, worker satisfaction, organizational commitment, the perceived support received, and the intention to expand IT use are negatively affected by the phenomenon (Ahmad et al., 2014; Fuglseth \& Sørebø, 2014; Ragu-Nathan et al., 2008, 2010; Tarafdar et al., 2007; Yan et al., 2013). Tarafdar et al. (2007) clarified that the presence of technostress also increases the general levels of occupational stress. Studying the context of teleworking, Suh and Lee (2017) identified that technostress is negatively related to the work satisfaction of professionals who act under this work modality. Lee et al. (2016), studying the stress generated by the use of mobile instant messaging after working hours, identified that this variation of stress caused by technology negatively affects workers' productivity and quality of life. Jena (2015) has found evidence that indicates that technostress negatively affects the work satisfaction and organizational commitment of teachers who use IT in the context of collaborative learning.

Most recently, Brooks and Califf (2017) identified that a specific type of technological stress, provoked by the use of social media at work, is negatively related to the performance of workers. Following this line, Hsiao, Shu, and Huang (2017) gathered evidence that the compulsive use of mobile applications is a new source of technostress. Maier, Laumer, \& Eckhardt. (2015), on the basis of previous studies (e.g., Ayyagari et al., 2011; Ragu-Nathan et al., 2008; Tarafdar et al., 2010), proposed a comprehensive model for technostress that integrates stressors, stress, and organizational outcomes. The authors identified that, ultimately, technostress has a broad impact at the organizational and individual levels, affecting, for example, job satisfaction, employee turnover intention, and organizational commitment. Directing their lens of analysis to the final phase of the use cycle of information systems, Maier, Laumer, Weinert, and Weitzel (2015) identified that the stress caused by the use of social networks is an antecedent to the intention of discontinuing the use of this technology.

Notwithstanding the fact that most of the literature on technostress focuses on the identification of the phenomenon through the use of questionnaires (Sellberg \& Susi, 2014), Riedl (2012) innovates by adopting a neurobiological approach to research. The author found evidence that the 
levels of cortisol, the hormone most related to stress in humans, increase before the occurrence of failures in information systems used by workers. In this regard, Tams et al. (2014), in comparing psychometric and physiological methods for stress measurement related to the use of IT, conclude that the complementary use of the two approaches allows a deeper and more holistic understanding of the problem. Following this line of reasoning, a recent study conducted by Baltaci and Gokcay (2016) collected evidence on the potential for detecting stress in computer users through pupil dilation and facial temperature. Sellberg and Susi (2014) also followed an unusual route to research on technostress by studying the phenomenon through a field study associated with the use of questionnaires. The authors concluded that the phenomenon is complex and multidimensional and suggest that researchers should use a mixed research approach.

Some researchers have turned their attention to the study of personality with regard to the use of IT. In this regard, Maier (2012) presents a comprehensive literature review that relates personality to research in the area of information systems. More specifically, some studies have analyzed the phenomenon of technostress from the personality characteristics of workers. For example, Krishnan (2017) identified several significant relationships between workers' responses to technostress and personality traits (the Big Five), in addition to the cultural dimensions of Hofstede. Finally, Hung, Chen, and Lin (2014) identified the role of proactive personality in minimizing the effects of communication overload caused by IT.

In this broad context, an approach frequently used in the literature is the operationalization of technostress by means of the measurement of the technostress creator factors (RaguNathan et al., 2008; Tarafdar et al., 2010). The authors propose that technostress can be measured in five different dimensions or types of negative effects perceived and reported by IT users: techno-overload (the feeling that they are increasingly working more and faster), techno-invasion (the feeling that it is necessary to sacrifice one's personal life), technocomplexity (the feeling that the technological environment is very complex), techno-uncertainty (the feeling that there are constant technological changes), and techno-insecurity (the fear of losing their jobs to someone who is technologically better prepared).

\subsection{Demographic characteristics in the use of IT}

Demographic or individual characteristics can influence the manner in which users perceive and react to the use of IT, but we still need to understand how this occurs (Zeithaml et al., 2002). For example, the influence of gender has been observed in several aspects relating to individuals' behavior, for example, emotions, motivation, and cognition (Gabriel \& Gardner, 1999; Saleem, Beaudry, \& Croteau, 2011). In this sense, there is evidence that women tend to be more oriented toward interpersonal relationships and are less likely to overestimate their job performance. Men, in turn, seem to be more performance oriented, more aggressive, and more competitive (Barnett \& Karson, 1989; Fletcher, 2001; Gabriel \& Gardner, 1999; Heinrich, 1991; Wahn, 2003).
Specifically in relation to the use of IT, in a study on the factors influencing the intention of new technology usage, Venkatesh and Morris (2000) identified that women tend to value more the aspects related to the ease of IT use and consider this issue when assessing the usefulness of a technological solution. Men, in turn, seem to be more orientated by the perception of the technology's utility, that is, how much users believe IT will impact their professional performance. In addition, men tend to be more influenced by extrinsic aspects related to the use of IT, while women are more sensitive to intrinsic aspects (Venkatesh et al., 2003). In differentiating IT professionals and IT users in the professional environment, Maier, Laumer and Eckhardt (2015) identified different results for the groups with regard to organizational results. More specifically, the researchers found that technologyinduced exhaustion has a direct effect on the job satisfaction, organizational commitment, and turnover intention of IT users, but for IT professionals, this effect is only indirect. Laumer, Maier, Eckhardt, and Weitzel (2016) studied employee resistance to IT-induced change and identified mixed results for the role of the variables gender, age, and professional experience in perceived ease of use, usefulness, and perceptual resistance to change.

Proceeding on the topic, Huffman, Whetten, and Huffman (2013) gathered studies that indicate that men exhibit more positive attitudes regarding the use of computers and a lower level of anxiety regarding the use of technology and are more comfortable with the use of computers (Coffin \& Macintyre, 1999; Cooper, 2006; Young, 2000). He and Freeman (2010) noted that women showed lower confidence and greater anxiety regarding the use of computers, and Çoklar and Şahin (2011) identified increased levels of technostress among women. However, in contrast, some studies have indicated that men are more prone to this type of technological stress (Ragu-Nathan et al., 2008; Tarafdar, Tu, Ragu-Nathan, \& RaguNathan, 2011). Studying the role of gender and personality traits in the potential impact of the hedonic use of computing platforms, Schwark, Dolgov, Hor, and Graves (2013) identified differences between the behavior of men and women as well as the effect of personality characteristics linked to neuroticism, narcissism, self-esteem, and extraversion. Other differences in relation to users' age, time of professional experience, and amount of formal education received are also frequently observed in the literature (Burton-Jones \& Hubona, 2005; Çoklar \& Şahin, 2011; Elie-Dit-Cosaque, Pallud, \& Kalika, 2011; Jena \& Mahanti, 2014; Joiner et al., 2013; Mikkelsen, Øgaard, Lindøe, \& Olsen, 2002; Morris, Venkatesh, \& Ackerman, 2005; Ragu-Nathan et al., 2008; Şahin \& Çoklar, 2009; Simon \& Usunier, 2007; Tarafdar et al., 2011; Venkatesh et al., 2003; Venkatesh, Thong, \& Xu, 2012).

The literature also suggests that younger generations cope better with IT than previous generations (Prensky, 2001; Zemke, Raines, \& Filipczak, 1999). Studies related to the acceptance of IT indicate that users' age is negatively related to their perception of the ease of use of technology (BurtonJones \& Hubona, 2005; Venkatesh et al., 2003). Zhou, Chourasia, and Vanderheiden (2017) identified that the need for metaphors used in the processes of developing mental models applied to reduce interaction problems related to the 
use of IT applications and services should be adapted for older users. Czaja and Sharit (1993) found higher levels of stress among older users when performing computer-mediated tasks. Recently, it has been understood that an antecedent of the acceptance and intent of IT usage is supporting conditions, that is, users' belief about the adequacy of the support they receive for the use of IT (Venkatesh et al., 2012). In this context, researchers have explained that users' age and gender are important moderating factors in this relationship, considering that older users tend to have greater difficulties in processing new and complex information, which can affect their ability to learn new technologies (Morris et al., 2005; Venkatesh et al., 2012). In this sense, Simon and Usunier (2007) observed that users' age is negatively related to their preference for the use of IT-based services. Similarly, older workers have reported higher levels of anxiety regarding the use of computers (Elie-Dit-Cosaque et al., 2011; Joiner et al., 2013; Mikkelsen et al., 2002) and higher levels of technostress (Çoklar \& Şahin, 2011; Jena \& Mahanti, 2014). On the other hand, younger users reported more technostress in the studies by Ragu-Nathan et al. (2008), Şahin and Çoklar (2009), and Tarafdar et al. (2011).

Other studies have found evidence of the moderating effect of users' educational level on their reactions to the use of IT (Agarwal \& Prasad, 1999; Elie-Dit-Cosaque et al., 2011; Mikkelsen et al., 2002; Ragu-Nathan et al., 2008; Tarafdar et al., 2011). Workers' educational level is related to various aspects of their organizational life, such as behaviors, beliefs, and professional performance (Ng \& Feldman, 2009). Holden and Rada (2011) indicated that in IT, users' educational level, among other factors, should be considered in studies related to users' behavior in relation to the acceptance of technology usage. Agarwal and Prasad (1999), for example, suggested that educational level may be indicative of the cognitive potential of users, facilitating the learning process of new technologies. In addition, users with higher levels of formal education are more exposed to the use of computers in general, which facilitates their technological adaptation (Tarafdar et al., 2011). In this sense, Elie-Dit-Cosaque et al. (2011) suggested that workers, in the course of their academic life, should acquire skills in the use of IT, becoming more comfortable with its use. In a study involving French IT workers, researchers found evidence that workers with higher levels of formal education suffer less anxiety regarding the use of IT. Agarwal and Prasad (1999) identified that the ease with which users use new technologies increases according to their educational level. According to Hsiao (2017), Krishnan (2017), RaguNathan et al. (2008), Tarafdar et al. (2011), users with a higher level of formal education report less technostress. Similarly, Mikkelsen et al. (2002) detected that anxiety regarding the use of computers is negatively related to education.

However, although several studies reported in the previous paragraphs indicate the importance of demographic variables for the use of IT, some studies did not detect this relationship (Hsiao et al., 2017; Korobili, Togia, \& Malliari, 2010; Maier et al., 2015; Maier, Laumer, Eckhardt, \& Weitzel, 2015; Parayitam, Desai, Desai, \& Eason, 2010; Scott \& Walczak, 2009; Wang, Shu, \& Tu, 2008). For example, Scott and Walczak (2009) did not observe significant differences in age in relation to users' self-efficacy regarding the use of computers. Similarly, Parayitam et al. (2010) found no influence of the variables age and gender on the levels of users' anxiety regarding the use of IT. Korobili et al. (2010) did not observe differences in the educational level of users with anxiety due to the use of computers or in their attitudes toward IT. The variables gender, age, and educational level did not have explanatory power over the general level of technostress in research conducted by Wang et al. (2008). Maier et al. (2015) did not detect differences in gender and age for the exhaustion provoked by the use of IT, even with IT professionals and users evaluating themselves. In the same vein, Hsiao et al. (2017) did not detect a strong influence of the gender variable on technostress, in contrast to what was expected by the authors. Maier et al. (2015) studied the social overload caused by the use of social networking sites, a type of stress provoked by the use of IT, but they did not find significance for the variables gender and age, in contrast to the authors' expectations. Although Hsiao (2017) detected a correlation between age and educational level and technostress, the author did not find the same effect for the gender variable. On the other hand, Krishnan (2017) did not find evidence of the effect of the variables age and gender on technostress but identified a slight effect of the level of formal education.

Thus, considering that the empirical evidence on the differences related to demographic characteristics and the results regarding IT usage in organizations are inconclusive and sometimes contradictory, this study is proposed to contribute to the debate, presenting new evidence obtained from the observation of these variables' behavior when compared with the technostress creator factors. In this regard, we expect that by adjusting the focus of the analysis for each of the measured subdimensions, this study will help broaden the understanding of the role of differences related to gender, age, educational level, and time of professional experience by IT users with regard to the result of the use of these technologies in organizations.

To summarize the results found in the previous surveys of the relationship between technostress and the demographic characteristics related to gender, age, and formal education, we elaborate Table 1. On the other hand, the scarcity of studies that relate the time of professional experience and that directly relate to technostress suggests that this is a gap to be filled in the literature.

\subsection{Hypotheses and research model}

Considering that previous studies have dealt with technostress in general, although the phenomenon is a second-order construct (Ragu-Nathan et al., 2008), as well as considering the need to clarify the controversial results of the literature, we chose to test each factor of technostress separately, deepening the results and seeking to clarify the divergences of the literature.

Thus, from the studies that indicate that the younger generations accept and deal better with new technology, they indicate to finding it easier and having a preference for the use of technology in daily activities, as well as presenting lower levels of stress and anxiety with the use of computers 
Table 1. Research on technostress and demographic characteristics.

\begin{tabular}{|c|c|c|c|}
\hline \multirow[b]{2}{*}{ RESEARCH } & \multicolumn{3}{|c|}{ DEMOGRAPHIC CHARACTERISTICS } \\
\hline & Gender & Age & Education \\
\hline Çoklar and Şahin (2011) & $\begin{array}{l}\text { More technostress among } \\
\text { women }\end{array}$ & More technostress among older workers & \\
\hline $\begin{array}{l}\text { Ragu-Nathan et al. } \\
\text { (2008) }\end{array}$ & More technostress among men & $\begin{array}{l}\text { More technostress among younger } \\
\text { workers }\end{array}$ & \\
\hline Tarafdar et al. (2011) & More technostress among men & $\begin{array}{l}\text { More technostress among younger } \\
\text { workers }\end{array}$ & $\begin{array}{l}\text { More technostress among workers with lower formal } \\
\text { education }\end{array}$ \\
\hline $\begin{array}{l}\text { Jena and Mahanti } \\
\text { (2014) }\end{array}$ & More technostress among men & More technostress among older workers & \\
\hline Şahin and Çoklar (2009) & & $\begin{array}{l}\text { More technostress among younger } \\
\text { workers }\end{array}$ & \\
\hline Wang et al. (2008) & Effect not detected & Effect not detected & Effect not detected \\
\hline Maier et al. (2015) & Effect not detected & Effect not detected & \\
\hline Hsiao et al. (2017) & Effect not detected & & \\
\hline Hsiao (2017) & Effect not detected & $\begin{array}{l}\text { More technostress among younger } \\
\text { workers }\end{array}$ & $\begin{array}{l}\text { More technostress among workers with lower formal } \\
\text { education }\end{array}$ \\
\hline Krishnan (2017) & Effect not detected & Effect not detected & $\begin{array}{l}\text { More technostress among workers with lower formal } \\
\text { education }\end{array}$ \\
\hline
\end{tabular}

to reduce interaction problems related to the use of IT applications and services (Burton-Jones \& Hubona, 2005; Czaja \& Sharit, 1993; Elie-Dit-Cosaque et al., 2011; Joiner et al., 2013; Mikkelsen et al., 2002; Morris et al., 2005; Prensky, 2001; Simon \& Usunier, 2007; Venkatesh et al., 2003, 2012; Zemke et al., 1999), we present the following research hypothesis:

H1: Compared to younger workers, older workers are more affected by (a) techno-overload, (b) techno-invasion, (c) techno-complexity, and (d) techno-uncertainty.

In spite of the lack of studies that have related technostress and professional experience, we expect that the time of experience of a worker is related to the age of the workers. Thus, according to the previous findings related to age, and considering that the time of professional experience is one of the main aspects of interest in the literature on diversity in the workforce (Van Knippenberg et al., 2004), we present the following research hypothesis:

H2: Compared to less experienced workers, more experienced workers are more affected by (a) techno-overload, (b) techno-invasion, (c) techno-complexity, and (d) technouncertainty.
From the studies that indicate that men present more positive attitudes, lower levels of anxiety, as well as feeling more comfortable and confident with the use of computers (Chua, Chen, \& Wong, 1999; Coffin \& Macintyre, 1999; Cooper, 2006; He \& Freeman, 2010; Huffman et al., 2013; Young, 2000), we present the following research hypothesis:

H3: Compared to men, women are more affected by (a) techno-overload, (b) techno-invasion, (c) techno-complexity, and (d) techno-uncertainty.

Finally, in view of studies that found evidence that people with a higher educational level tend to adapt and learn to new technologies better and more easily, as well as having lower levels of anxiety and feeling more comfortable with the use of computers (Agarwal \& Prasad, 1999; Elie-Dit-Cosaque et al., 2011; Mikkelsen et al., 2002; Tarafdar et al., 2011; Venkatesh \& Morris, 2000), we present the following research hypothesis:

H4: Compared with workers with a higher level of formal education, workers with lower levels of formal education are more affected by (a) techno-overload, (b) techno-invasion, (c) techno-complexity, and (d) techno-uncertainty.

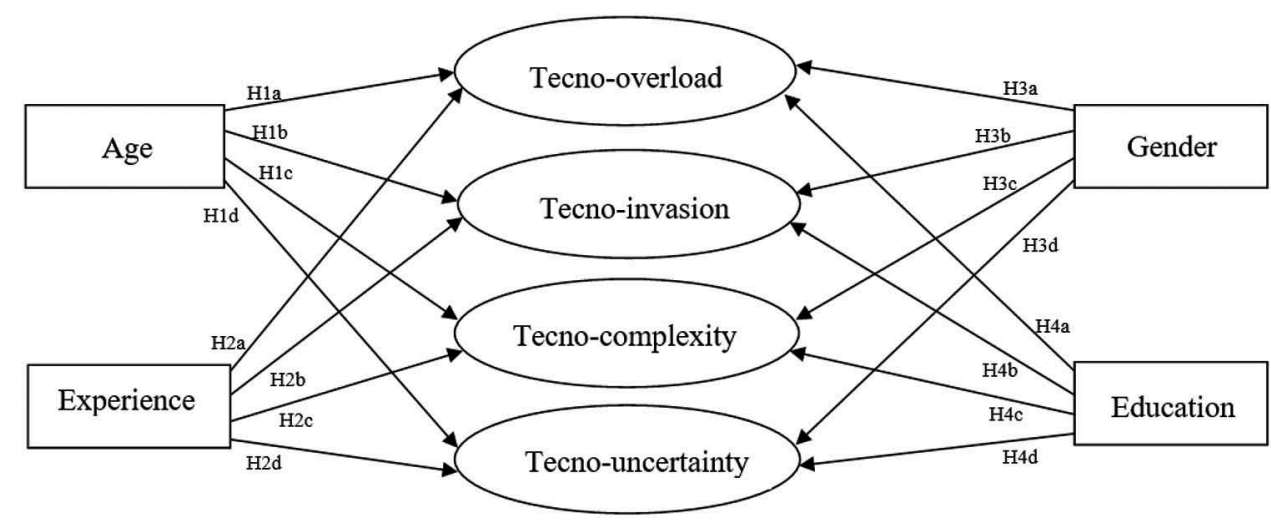

Figure 1. Research model. 
In this sense, the hypotheses developed for the present study can be represented by the research model presented in Figure 1.

\section{Methodology}

For the present study, we adopted a quantitative approach, considering that users' perceptions were represented by numerical data, facilitating statistical analysis of the data collected. The research is descriptive, given that it was based on a structured plan that measured the characteristics described in the investigated research problem. To that end, we conducted a crosssectional analysis since the data were collected exclusively between the months of November and December 2014. The data can be classified as primary and subjective: primary because they were collected specifically to complete the research project, and subjective because they reflect the opinions of the participants (Hair, Babin, Money, \& Samouel, 2005).

Fourteen public Brazilian institutions, all with high rates of IT use in their organizational processes, agreed to participate. The workers of these public institutions, linked to the Brazilian judiciary, basically work on two lines of action. The first is related to the direct service provided to citizens, especially the receiving and processing of their legal claims. The second line of action is related to support activities such as human resource management, accounting, and finance. In addition, all agencies contained internal departments to provide IT services to users, thus justifying why they were chosen. Approximately 4500 users received an invitation via e-mail to participate in the research. A total of 940 people sent their answers through the completion of an electronic form. However, after preliminary analysis of the replies, we decided to withdraw 13 questionnaires that were filled out incompletely. Thus, the final sample contained 927 questionnaires, which represents a response rate of $20.3 \%$. The questionnaires were administered between the months of November and December 2014.

The questionnaire used to measure the technostress creator factors is based on the instrument presented by Tarafdar et al. (2007). More specifically, the variable techno-overload (TOV) was measured by five questions. For techno-invasion (TIV), we used four questions. Techno-complexity (TCO) was measured by five questions. Finally, four questions measured techno-uncertainty (TUC). In all cases, we used a 5-point Likert scale ranging from "totally disagree" to "totally agree." However, we opted to remove from the questionnaire items referring to the construct of techno-insecurity. This decision was because the sample was exclusively composed of public servants who have the right to job security, as guaranteed by the Brazilian Federal Constitution. Thus, considering that, in essence, techno-insecurity captures the fear that workers report of losing their jobs and being replaced by other workers who are more technologically skilled, the inclusion of techno-insecurity could generate a bias in the analyses, compromising the results.

To gather additional information necessary to achieve the objective of this study, we included questions regarding variables related to the individual characteristics gender (GEN), age (AGE), level of formal instruction (EDU), and length of professional experience (EXP). Thus, the applied questionnaire contained a total of 24 questions, and for questions related to technostress, we offered the answer option of "I do not know or non-applicable." Before the questionnaires were administered, they were submitted to a group of six users to verify the understanding of the questions, with no problems being registered (Hair et al., 2005).

To perform quantitative analyses, we calculated the proportion measures, descriptive statistics (mean and standard deviation), and the questionnaire's internal consistency indexes (Cronbach's alpha). As a support tool, we used SPSS 22.0. Then, the existence of differences between user groups identified on the basis of gender, age, educational level, and length of professional experience was investigated by the specification of a multiple imputation and multiple causes (MIMIC) model, using structural equations modeling (SEM), as proposed by Joreskog and Goldberger (1975). This is an agile method of identifying differences between groups through the use of dummy variables in a causal model (Marôco, 2014). Thus, for the variable gender, we established a value of 0 for women and 1 for men. For the variable formal instruction, we established a value of 0 for the group with less formal education (graduate or less) and 1 for respondents with specialization (lato sensu), master's degrees and doctorates. To create groups based on the age criteria, we considered 39 years of age a point of delimitation, considering that people at that age, or younger, generally started their professional life after the beginning of IT usage in professional environments (these were identified with a value of 1). Thus, it is possible to analyze the differences between these people and those who have worked without IT support (they received a value of 0 ). Finally, for the variable experience, we established a value of 0 for the group with a lower number of years worked in the agency (up to 10 years) and 1 for respondents with longer experience (11 years or more). The structural models were specified in the IBM AMOS version 22 package.

\section{Data analysis and discussion}

Data analysis began with the characterization of the sample presented in Table 2 .

Given the answers by the participants, they can be characterized as follows:

Table 2. Summary of sample characterization.

\begin{tabular}{llrr}
\hline DEMOGRAPHIC VARIABLE & ANSWER OPTION & FREQ. & \multicolumn{1}{c}{$\%$} \\
\hline Gender & Male & 528 & 56.96 \\
Age & Female & 399 & 43.04 \\
& $20-29$ years old & 69 & 7.44 \\
& $30-39$ years old & 377 & 40.67 \\
Educational level & $40-49$ years old & 319 & 34.41 \\
& Above 50 years old & 162 & 17.48 \\
& Secondary school & 57 & 6.15 \\
& Graduate & 269 & 29.02 \\
Professional experience & Specialization & 543 & 58.58 \\
& MSc or PhD & 54 & 5.83 \\
& Other & 4 & 0.43 \\
& Up to 5 years & 161 & 17.37 \\
& 6-10 years & 450 & 48.54 \\
& $11-15$ years & 60 & 6.47 \\
& $16-20$ years & 169 & 18.23 \\
& Above 20 years & 87 & 9.39 \\
\hline
\end{tabular}


- Most of the 927 participants are male (56.96\%), and $43.04 \%$ are female;

- The majority completed a specialization course (postgraduate lato sensu), representing $58.58 \%$ of the answers;

- There was a predominance of participants with ages ranging between 30 and 39 years (40.67\%) and who have worked at the institution between 6 and 10 years.

We did not identify trends or absolute majorities in the sample that could interfere in the results. We also did not observe significant differences in the distribution of the characteristics of the sample and population servers in a comparison of available data on the basis of human resource agencies. The data on the participants' gender and age allow us to determine that the research respondent is the typical user of the organization, given that there were no biases or tendencies observed that may compromise the representativeness of the sample. For the same observation, information related to the time of experience in the organization is established since it is compatible with civil service examination periods to fill vacancies. Similarly, the prevalence of users that completed specialization courses $(58.59 \%)$ is explained by an organizational strategy shared between the 14 researched agencies that grants financial incentives to employees who complete specialization courses. Thus, we can conclude that the sample collected is appropriate for the objectives of the study.

The evaluation of the variables related to technostress (Ragu-Nathan et al., 2008; Tarafdar et al., 2007) revealed that, in general, the averages found were low, which suggests that this problem does not appear to be particularly relevant in the opinion of the population surveyed (Table 3). For example, the lowest mean among the research variables $(M=1.65)$ was detected in the construct of techno-invasion (TIV). That is, the surveyed users stated that their personal lives are not being heavily invaded by the use of IT in their organizations. In addition, this was a homogeneous opinion $(\mathrm{SD}=0.78)$. Although all of the items of the variable presented low means, some users reported that they have contact with work, even during their vacations, because of the IT used in the organization. This statement is based on the fact that this item presented the highest mean of the construct $(M=1.96)$ and a high degree of discrepancy in the responses $(\mathrm{SD}=1.24)$.

Similarly, users did not report facing many difficulties with the complexity of the technological environment that they use at work. This is what the mean of 2.02, identified for the techno-complexity (TCO) variable, and the standard deviation of 0.86 suggest. Among the items that compose the construct, what stands out is the users feel that they do not have enough time to study or to keep technologically up-todate $(M=2.31)$, a nonconsensual opinion $(\mathrm{SD}=1.22)$. On the other hand, the item with the lowest impact was the opinion that the users find understanding and using new technologies to be complex $(M=1.82)$. The result of the techno-overload (TOV) variable appeared to be more noticeable though still inconsistent, with a mean of 2.31 . The data suggest that users do not realize how important the intricacies related to the increased volume of work provided by the use of IT in their organizations are. The data suggest that users do not realize how important the difficulties that they face are related to the increase in work volume provided by the use of IT in their organizations. However, this is not a homogeneous opinion, given the detection of a standard deviation of 1.04, the largest among the variables studied. Thus, the data indicate that a share of users reported being subject to this problem, which can be explained by the use of different technological solutions by the internal departments of public agencies and by the irregular workload distribution between the areas of the organization. Finally, the techno-uncertainty (TUC) variable presented the highest mean among the four technostressrelated variables, reaching a value slightly higher than neutrality $(M=3.07)$, and a high degree of convergence of opinions $(\mathrm{SD}=0.88)$. In this construct, which is related to the constant changes in the organization's technological environment, we highlight the item concerning the constant evolution of the technological environment applied by users $(M=3.62$ and $\mathrm{SD}=1.13)$. It is worth noting that the values found were very similar to those obtained by the item that measured the degree of innovation of the services provided by the IT department $(M=3.50$ and $\mathrm{SD}=1.01)$ present in the product service construct.

Table 3. Descriptive statistics.

\begin{tabular}{|c|c|c|c|}
\hline CODE & DESCRIPTION & $M$ & SD \\
\hline TOV1 & $\begin{array}{l}\text { I am forced to work faster because of the information } \\
\text { technology used at work }\end{array}$ & 2.47 & 1.31 \\
\hline TOV2 & $\begin{array}{l}\text { I am forced to work more than I can stand because of the } \\
\text { information technology used at work }\end{array}$ & 2.00 & 1.20 \\
\hline TOV3 & $\begin{array}{l}\text { I am forced to work with very tight schedules because of } \\
\text { the information technology used at work }\end{array}$ & 2.29 & 1.27 \\
\hline TOV4 & $\begin{array}{l}\text { I am forced to change my work habits to adapt to new } \\
\text { technologies }\end{array}$ & 2.65 & 1.36 \\
\hline TOV5 & $\begin{array}{l}\text { I have a larger workload due to increased technological } \\
\text { complexity }\end{array}$ & 2.12 & 1.31 \\
\hline TECHN & O-OVERLOAD MEAN & 2.31 & 1.04 \\
\hline TIV1 & $\begin{array}{l}\text { I spend less time with my family because of the } \\
\text { information technology used at work }\end{array}$ & 1.61 & 1.02 \\
\hline TIV2 & $\begin{array}{l}\text { I am in contact with work even during vacation because } \\
\text { of the information technology used at work }\end{array}$ & 1.96 & 1.24 \\
\hline TIV3 & $\begin{array}{l}\text { I have to sacrifice my vacation time and weekends to keep } \\
\text { myself up-to-date with new technologies }\end{array}$ & 1.50 & 0.89 \\
\hline TIV4 & $\begin{array}{l}\text { I feel that my personal life is being invaded because of the } \\
\text { information technology used in at work }\end{array}$ & 1.51 & 0.90 \\
\hline TECHN & IO-INVASION MEAN & 1.65 & 0.78 \\
\hline TCO1 & $\begin{array}{l}\text { I do not know enough about information technology to } \\
\text { satisfactorily address my work }\end{array}$ & 1.91 & 1.09 \\
\hline TCO2 & $\begin{array}{l}\text { I need a long time to understand and use new } \\
\text { technologies }\end{array}$ & 1.79 & 1.03 \\
\hline TCO3 & $\begin{array}{l}\text { I do not find enough time to study and catch up with } \\
\text { technology }\end{array}$ & 2.31 & 1.22 \\
\hline TCO4 & $\begin{array}{l}\text { I think the newcomers of this organization know more } \\
\text { about technology than I do }\end{array}$ & 2.27 & 1.27 \\
\hline TCO5 & $\begin{array}{l}\text { I often find understanding and using new technologies to } \\
\text { be very complex }\end{array}$ & 1.82 & 1.02 \\
\hline TECHN & IO-COMPLEXITY MEAN & 2.02 & 0.86 \\
\hline TUC1 & $\begin{array}{l}\text { The technologies used in our organization are always } \\
\text { evolving }\end{array}$ & 3.62 & 1.13 \\
\hline TUC2 & $\begin{array}{l}\text { There are constant changes in the software (programs, } \\
\text { systems, application, etc.) used in our organization }\end{array}$ & 3.19 & 1.10 \\
\hline TUC3 & $\begin{array}{l}\text { There are constant changes in the equipment (computers, } \\
\text { printers, scanners, etc.) used in our organization }\end{array}$ & 2.93 & 1.15 \\
\hline TUC4 & $\begin{array}{l}\text { There are frequent changes in the computer networks } \\
\text { used in our organization }\end{array}$ & 2.56 & 1.06 \\
\hline \multicolumn{2}{|c|}{ TECHNO-UNCERTAINTY MEAN } & 3.03 & 0.88 \\
\hline
\end{tabular}


Comparing the results obtained in this research with the data obtained by Tarafdar et al. (2007) and Ragu-Nathan et al. (2008), several similarities were also identified (Table 4). In general, the levels of technostress detected in the three surveys were low, and in all three cases, the variable techno-complexity was the variable achieving the highest score. Similarly, the techno-invasion variable obtained the lowest mean in all three studies. The standard deviations were also drawn near and overall indicated a reasonable level of agreement among the participants. Finally, the reliability indicators of the constructs were located in similar levels, slightly lower than those found in the three variables of service encounter but with proper consistency.

Despite the similarity between results, we observed that the levels of technostress highlighted in this study were lower than those presented in Table 4 . In addition to the differences related to the technological environment of the surveyed organizations, a possible explanation for the observed technostress reduction in the four studied factors may be in the fact that seven years have passed since the completion of previous studies. During this period, users experienced the use of IT in their professional and personal lives intensively, in such a way that technology is already part of their lives. Thus, the data suggest that users may have become accustomed to the use of IT, which may have caused a reduction in the levels of technostress. Finally, Cronbach's alpha analysis indicates the reliability of the internal coherence of the instrument used in the research, whereas all of the values found

Table 4. Comparison of the technostress creator factors.

\begin{tabular}{|c|c|c|c|c|c|c|c|c|c|}
\hline \multirow[b]{2}{*}{ Variable } & \multicolumn{3}{|c|}{$\begin{array}{c}\text { Tarafdar et al. } \\
(2007)\end{array}$} & \multicolumn{3}{|c|}{$\begin{array}{l}\text { Ragu-Nathan } \\
\text { et al. (2008) }\end{array}$} & \multicolumn{3}{|c|}{$\begin{array}{l}\text { Data from the } \\
\text { present research }\end{array}$} \\
\hline & $\%$ & SD & $a$ & $\%$ & SD & $a$ & $\%$ & SD & $a$ \\
\hline Techno-overload & 49.25 & 1.00 & 0.89 & 50.00 & 0.91 & 0.82 & 32.75 & 1.04 & 0.86 \\
\hline Techno-invasion & 22.75 & 0.77 & 0.81 & 30.25 & 0.83 & 0.80 & 16.25 & 0.78 & 0.77 \\
\hline Techno-complexity & 38.50 & 0.83 & 0.84 & 42.75 & 0.75 & 0.77 & 25.50 & 0.86 & 0.82 \\
\hline Techno-uncertainty & 53.75 & 0.80 & 0.82 & 58.25 & 0.76 & 0.83 & 51.75 & 0.88 & 0.80 \\
\hline
\end{tabular}

were located between 0.77 and 0.86 , greater than the minimum recommended value of 0.70 (Hair et al., 2005).

To detect whether the answers of the respondents classified by gender, age, educational level, and time of experience presented means with significant differences, we performed comparisons through the specification of five structural equation models (SEM), with each being specifically built for each variable in the study. To allow the use of the MIMIC approach, we specified a second-order structural equation model for the technostress construct, in conjunction with the four dummy variables related to the individual characteristics analyzed, according to Figure 2. After making the necessary adjustments to the model, the goodness-of-fit indices obtained can be considered acceptable, as described in Marôco (2014): $\chi^{2} / \mathrm{df}(190)=874.980 ;$ CFI $=0.911 ;$ PCFI $=0.750$; GFI $=0.920$; PGFI $=0.691$ RMSEA $=0.062$; and SRMR $=0.055$.

The analysis of the regressions weights indicated that the four technostress creator factors studied in this article were significant (0.05 level), corroborating Tarafdar et al. (2007) and Ragu-Nathan et al. (2008). Table 5 presents the estimates obtained.

\subsection{Age}

Table 6 presents the estimates obtained for the age variable, related to each of the four technostress creator factors. Users under 39 years of age were grouped $(N=446)$, as were those over this age limit $(N=481)$. This division allowed users to be grouped into those who started their professional careers before the diffusion of IT in organizations compared to respondents who started their careers after this diffusion. Thus, a dummy variable was specified to represent older users.

Regarding the effect of the age of the workers on technostress $(\mathrm{H} 1)$, we tested hypotheses that when compared to younger workers, older workers are more affected by (a)

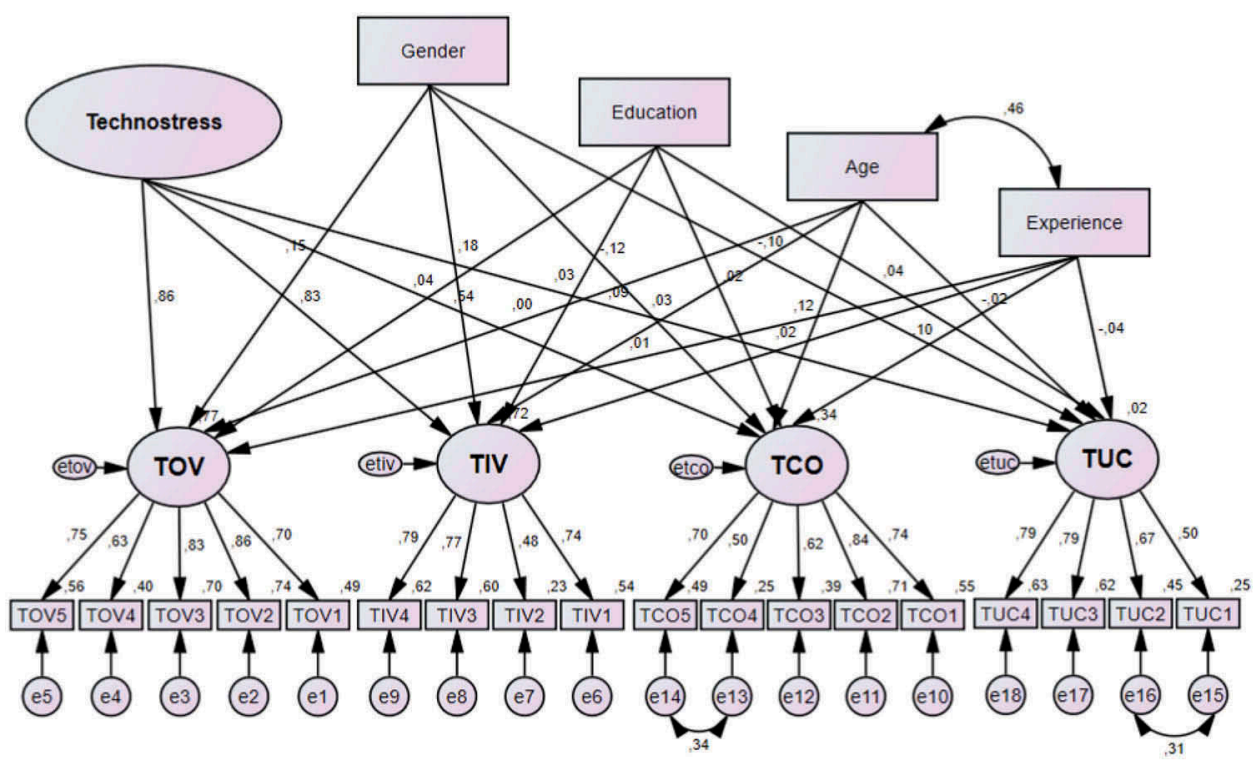

Figure 2. Structural model.

TOV: Techno-overload; TIV: Techno-invasion; TCO: Techno-complexity; TUC: Techno-uncertainty 
Table 5. Estimates for technostress.

\begin{tabular}{lllccccc}
\hline & & \multicolumn{4}{c}{ REGRESSION WEIGHTS } & & STANDARDIZED \\
\cline { 3 - 5 } & & Estimate & S.E. & C.R. & $P$ & & Estimate \\
\hline TOV & $<-$ & Technostress & 0.786 & 0.045 & 17.548 & $* * *$ & \\
TIV & $<-$ & & 0.624 & 0.035 & 17.591 & $* * *$ & 0.862 \\
TCO & $<-$ & 0.434 & 0.033 & 13.244 & $* * *$ & 0.829 \\
TUC & $<-$ & 0.05 & 0.023 & 2.158 & 0.031 & & 0.536 \\
\hline
\end{tabular}

TOV: Techno-overload; TIV: Techno-invasion; TCO: Techno-complexity; TUC: Techno-uncertainty

Table 6. Estimates for age.

\begin{tabular}{|c|c|c|c|c|c|c|c|}
\hline & & & \multicolumn{4}{|c|}{ REGRESSION WEIGHTS } & \multirow{2}{*}{$\frac{\text { STANDARDIZED }}{\text { Estimate }}$} \\
\hline & & & Estimate & S.E. & C.R. & $P$ & \\
\hline TOV & $<-$ & Age & -0.002 & 0.071 & -0.035 & 0.972 & -0.001 \\
\hline TIV & $<-$ & & 0.052 & 0.061 & 0.85 & 0.395 & 0.034 \\
\hline TCO & $<-$ & & 0.196 & 0.064 & 3.062 & 0.002 & 0.121 \\
\hline TUC & $<-$ & & -0.02 & 0.046 & -0.437 & 0.662 & -0.018 \\
\hline
\end{tabular}

TOV: Techno-overload; TIV: Techno-invasion; TCO: Techno-complexity; TUC: Techno-uncertainty

techno-overload, (b) techno-invasion, (c) techno-complexity, and (d) techno-uncertainty. In this sense, the evidence supported hypothesis H1c and did not support hypotheses H1a, H1b, and H1d. More precisely, we detected a difference related to the age of users: the results suggest that older users tend to perceive the organizational technology environment (techno-complexity) to be more complex than younger users. This finding is consistent with the studies by Şahin and Çoklar (2009) and Jena and Mahanti (2014) but contradicts the results found by Ragu-Nathan et al. (2008), Tarafdar et al. (2011), and Çoklar and Şahin (2011). A possible explanation is the fact that younger people are more familiar with the use of various technologies, which can cause the reduction in the perception of the complexity of the technological environment. New generations use technological devices from a very young age and more often (Prensky, 2001). For example, Joiner et al. (2013) identified that younger users use the Internet more, in terms of frequency and amplitude, than previous generations. However, Helsper and Eynon (2010) warned that users' age is one of the factors that should be considered in this regard, in addition to gender, education, experience, and the amplitude of IT use. Finally, no significant differences for the remaining technostress creator factors (techno-overload, techno-invasion, and techno-uncertainty) were found.

\subsection{Professional experience}

Table 7 presents the estimates obtained for the variable professional experience, related to each of the four technostress

Table 7. Estimates for professional experience.

\begin{tabular}{lllllllc}
\hline & & \multicolumn{4}{c}{ REGRESSION WEIGHTS } & & \multicolumn{2}{c}{ STANDARDIZED } \\
\cline { 3 - 5 } & & Estimate & S.E. & C.R. & $P$ & & Estimate \\
\hline TOV & $<-$ & Professional & 0.026 & 0.075 & 0.349 & 0.727 & 0.014 \\
TIV $<-$ & experience & 0.033 & 0.064 & 0.522 & 0.602 & 0.021 \\
TCO $<-$ & & 0.166 & 0.067 & 2.464 & 0.014 & 0.097 \\
TUC $<-$ & & -0.051 & 0.049 & -1.047 & 0.295 & & -0.043 \\
\hline
\end{tabular}

TOV: Techno-overload; TIV: Techno-invasion; TCO: Techno-complexity; TUC: Techno-uncertainty creator factors. The division between the groups added users with longer professional experience in the public institutions surveyed $(N=316)$ and compared them with the group of users who have worked for less time in the organizations $(N=611)$. Thus, a dummy variable was specified to represent users with longer professional experience.

Regarding the effect of workers' time of professional experience on technostress ( $\mathrm{H} 2)$, we tested hypotheses that, when compared to less experienced workers, more experienced workers are more affected by (a) techno-overload, (b) techno-invasion, (c) techno-complexity, and (d) technouncertainty. In this sense, the evidence supported hypothesis $\mathrm{H} 2 \mathrm{c}$ and did not support hypotheses $\mathrm{H} 2 \mathrm{a}, \mathrm{H} 2 \mathrm{~b}$, and $\mathrm{H} 2 \mathrm{~d}$. More precisely, we did not observe any relationship between users' professional experience and the factors techno-overload, techno-invasion, and techno-uncertainty. However, a positive relationship between users' professional experience and the techno-complexity problem was detected. That is, the longer the users' length of professional experience is, the more these users are affected by this problem. A possible explanation may be related to the fact that in the surveyed institutions, users with more experience in general are older professionals. Thus, this result is coherent with what was detected in relation to the age variable in this study.

\subsection{Gender}

Table 8 presents the estimates obtained referring to the gender variable, related to each of the four technostress creator factors. The users were divided between women $(N=399)$ and men $(N=528)$. A dummy variable was specified to represent male users.

Regarding the effect of the gender of workers on technostress (H3), we tested the hypothesis that when compared to men, women are more affected by (a) techno-overload, (b) techno-invasion, (c) techno-complexity, and (d) technouncertainty. In this regard, evidence supported hypothesis $\mathrm{H} 3 \mathrm{c}$ and H3d, but did not support hypotheses H3a and H3b. The data indicated that technostress can be influenced by gender differences, supporting the findings by Tarafdar et al. (2011), Ragu-Nathan et al. (2008), Çoklar and Şahin (2011), and Jena and Mahanti (2014). Surprisingly, however, women and men were differently affected by the phenomenon. Women reported being subject to higher levels of techno-complexity and techno-uncertainty, while men indicated feeling greater effects from techno-overload and technoinvasion. These findings seem to be related to the evidence indicating that men are more oriented toward extrinsic aspects regarding the use of IT while women are more sensi-

Table 8. Estimates for gender.

\begin{tabular}{lllllllc}
\hline & & \multicolumn{4}{c}{ REGRESSION WEIGHTS } & & STANDARDIZED \\
\cline { 3 - 5 } & & Estimate & S.E. & C.R. & $P$ & & Estimate \\
\hline TOV & $<-$ & Gender & 0.285 & 0.064 & 4.442 & $* * *$ & \\
TIV & $<-$ & & 0.276 & 0.055 & 5.034 & $* * *$ & 0.155 \\
TCO & $<-$ & & -0.198 & 0.058 & --3.449 & $* * *$ & 0.182 \\
TUC & $<-$ & -0.11 & 0.042 & --2.622 & 0.009 & -0.121 \\
\hline
\end{tabular}

TOV: Techno-overload; TIV: Techno-invasion; TCO: Techno-complexity; TUC: Techno-uncertainty 
tive to intrinsic aspects (Venkatesh et al., 2003). In this sense, among the technostress creator factors, techno-overload and techno-invasion are the most closely related to external aspects of the phenomenon (increasing workload and invasion of private life), while techno-complexity and technouncertainty refer to internal factors of the problem (difficulties with the complexity of and with the constant changes in the technological environment being used).

\subsection{Educational level}

Table 9 presents the estimates obtained for the variable of educational level, related to each of the four technostress creator factors. The division between the groups added users who have studied up to the undergraduate level $(N=330)$ and compared them with the group of users who have a specialization or completed their master's degree or doctorate $(N=597)$. Thus, a dummy variable was specified to represent users with a higher level of formal education.

Regarding the effect of workers' level of formal education on technostress (H4), we tested the hypothesis that when compared to workers with higher level of formal education, workers with lower levels of formal education are more affected by (a) technooverload, (b) techno-invasion, (c) techno-complexity, and (d) techno-uncertainty. Nonetheless, we did not observe any relationship between users' educational level and the four technostress creator factors (hypotheses $\mathrm{H} 4 \mathrm{a}, \mathrm{H} 4 \mathrm{~b}, \mathrm{H} 4 \mathrm{c}$, and $\mathrm{H} 4 \mathrm{~d}$ ), which is consistent with the findings by Wang et al. (2008) and contradicts those found by Ragu-Nathan et al. (2008), Tarafdar et al. (2011), Hsiao (2017), and Krishnan (2017).

In summary, considering the five analyses carried out, the results suggest that the individual differences related to gender, age, educational level, and users' length of professional experience presented significant differences when related to the different aspects (or factors) of stress caused by IT usage in organizations. However, the results indicate that, aiming at a broader understanding of the problem, these demographic characteristics should be examined individually and must be connected one by one with the technostress creator factors.

In general, we observe that the effects of a particular demographic characteristic vary according to each factor of technostress, taken in isolation. In some cases, the analysis of a given characteristic produced the opposite results according to different stressors (for example, for the gender of the respondents). That is, managers and future researchers should be aware that a broader and deeper understanding of technostress necessarily involves a detailed analysis of the effect of each of its components on the variables or associated constructs.

Table 9. Estimates for formal education.

\begin{tabular}{|c|c|c|c|c|c|c|c|}
\hline & & & \multicolumn{4}{|c|}{ REGRESSION WEIGHTS } & \multirow{2}{*}{$\frac{\text { STANDARDIZED }}{\text { Estimate }}$} \\
\hline & & & Estimate & S.E. & C.R. & $P$ & \\
\hline TOV & $<-$ & Educational & 0.085 & 0.066 & 1.287 & 0.198 & 0.044 \\
\hline TIV & $<-$ & level & 0.051 & 0.056 & 0.901 & 0.367 & 0.032 \\
\hline TCO & $<-$ & & 0.034 & 0.059 & 0.574 & 0.566 & 0.02 \\
\hline TUC & $<-$ & & 0.046 & 0.043 & 1.078 & 0.281 & 0.039 \\
\hline
\end{tabular}

TOV: Techno-overload; TIV: Techno-invasion; TCO: Techno-complexity; TUC: Techno-uncertainty
In view of the contradictory results observed in the literature on the effect of the association of demographic and technostress characteristics, we needed to find possible explanations. To do so, we used the literature on the diversity of the workforce, coming from the field of applied psychology. In this regard, Roberson et al. (2017) present a comprehensive review of the literature of the field, from which we were able to identify that the degree of distribution of differences within organizations can affect the outcome of the variables of interest (Williams \& O'Reilly III, 1998). That is, the analysis of very different groups, in terms of demographic characteristics, may produce highly different results. Another possible explanation may be related to the fact that individuals may be identified more (or less) with demographically marked subgroups than with larger groups, which can cause changes in the functioning of the groups, including responses to external stimuli (Lau \& Murnighan, 1998). In addition, different organizational contexts can impact the results of studies. In this regard, Joshi and Roh (2009) examined the role of contextual factors in the research of the diversity of the workforce and warned that the variation in the research contexts, such as the types of market, occupation, or team, can lead to significant changes in the results of field studies at the organizational and individual levels. In this respect, previous research has alerted us to the importance of personality traits and cultural aspects in research on the beliefs, perceptions, and results concerning the use of IT in organizations (Krishnan, 2017; Maier, 2012).

\section{Conclusion}

The objective of this study was to determine whether the individual characteristics of gender, age, educational level, and users' length of professional experience produce differences in relation to users' perception of the technostress creator factors. The results indicated that the stress caused by the use of IT in organizations affects users in the most varied ways and those individual characteristics strongly influence the manifestation of the phenomenon. More specifically, the results of this study indicated that the longer the users' length of professional experience is, the more they will be affected by the perception of the complexity of the professional technological environment (techno-complexity), an issue that was also impacting older users. In relation to gender differences, women reported being more exposed to higher levels of techno-complexity and techno-uncertainty, while men seemed to suffer more from the effects of techno-overload and technoinvasion. Finally, we did not observe any relationship between users' educational level and the four technostress creator factors among the users of the surveyed public institutions.

Because the body of previous research that studies the problem of technostress faced by workers is aligned with itself (e.g., Ahmad et al., 2014; Ayyagari et al., 2011; Fuglseth \& Sørebø, 2014; Jena, 2015; Krishnan, 2017; Lee et al., 2016; Maier, 2014; Maier et al., 2015; Ragu-Nathan et al., 2008; Riedl, 2012; Suh \& Lee, 2017b; Tams et al., 2014; Tarafdar et al., 2007, 2010; Yan et al., 2013), the present study adjusts its focus of analysis specifically to the relationship of each creator of technostress (Ragu-Nathan et al., 2008), with the variables gender, age, professional experience, and formal education being among the most commonly presented topics 
in the literature on workforce diversity (Van Knippenberg et al., 2004). In this regard, several contributions can be drawn for the theory and management of IT services in organizations. In the theoretical field, the study results explicitly state that demographic differences can significantly alter the levels of technostress reported by users. Therefore, future research can consider the impact of this influence when relating the phenomenon to variables at the organizational and individual levels. However, the association between technostress and the individual characteristics studied is differentiated. In contrast, the results noted that this association must be made in a specific manner, relating the demographic characteristics to each specific stressor.

In this sense, the results of the present study provide elements that may help understand the seemingly contradictory results observed in previous research, which at times points to the existence of differences related to demographic characteristics or gathers evidence in the opposite direction. More specifically, rescuing the divergences of the results in previous research (presented in Table 1), Ragu-Nathan et al. (2008), Tarafdar et al. (2011), and Jena and Mahanti (2014) identified higher levels of technostress among men, while the evidence obtained by Çoklar and Şahin (2011) indicates the opposite (more technostress among women); in addition, the results presented by Wang et al. (2008), Maier et al. (2015), Hsiao et al. (2017), Hsiao (2017), and Krishnan (2017) did not find significant results. In the present study, the results indicate that the gender variable is affected in a mixed manner; that is, men are subject to higher levels of techno-overload and techno-invasion, whereas technouncertainty and techno-complexity seem to affect women more. The evidence from the literature is also contradictory for the age variable: Çoklar and Şahin (2011) and Jena and Mahanti (2014) detected higher levels of technostress among older workers, whereas Ragu-Nathan et al. (2008), Tarafdar et al. (2011), and Hsiao (2017) found evidence in the opposite direction (more technostress among youth). The results of the present study indicate that only one of the four analyzed technostress creator factors was significant (techno-complexity), affecting older workers more intensely. Finally, for Tarafdar et al. (2011), workers with higher levels of formal education are more subject to technostress, while Hsiao (2017) and Krishnan (2017) found contradictory evidence (more technostress among the less educated). On the other hand, the results of the present study did not find significant effects between the technostress creator factors and the level of formal education of the users, corroborating the results obtained by Wang et al. (2008).

In the practical field, the results of this study help IT managers understand the role of individual differences in the context of technostress, subdivided by the technostress creator factors. IT managers are provided with information that can contribute to the adoption of problem-solving actions designed specifically for each audience. In addition, this information can serve as a basis for the training of technical staff, with a focus on understanding the reactions and needs of each subset of users, segmented by gender, age, level of formal education, and time of experience. We identified, for example, that older workers suffer more from problems related to the complexity of the technological environment. With this in mind, professionals and IT managers must direct efforts and investments to increase the usability of IT solutions, making the technological environment simpler and more intuitive. Another possibility to meet the needs of older workers is the specialization of support professionals for the service of this public. In addition, older workers could receive specialized training on new and future solutions, with a strong emphasis on practical activities. Therefore, as highlighted by Ayyagari et al. (2011), understanding the factors that help explain the origins and consequences of the technostress can guide managers to adopt interventions with the objective of reducing the costs associated with the existence of people with stress in organizations

The study, however, has limitations that contraindicate the generalization of the results. First, the data were collected by means of a non-probabilistic sampling process and defined by convenience, considering that the respondents' participation was voluntary. Second, the investigation focused on public sector bodies, which, as noted by evidence in the literature (Baarspul \& Wilderom, 2011; Rainey \& Chun, 2007), have operating dynamics, especially on the organizational level, that are very diverse in private organizations. From these limitations, we suggest that subsequent studies include private and third sector organizations and expand investigations to other geographical and cultural contexts so that the results can be compared with those obtained by the present study. By also considering the different results found in the literature, we suggest that future researchers deepen the analysis of the relationship between the individual characteristics and technostress, general and relative to its creator factors, through the study of the influence of technological, contextual, and social contexts in which the workers are involved (Elie-Dit-Cosaque et al., 2011; Joshi \& Roh, 2009; Krishnan, 2017; Maier, 2012). We also suggest studies that investigate the role of individual characteristics in technostress under different contexts relating to the use of IT in organizations, as proposed by Yeo and Gold (2015): standardization (full IT use), hybridization (partial IT use), and conventionalization (disuse of IT).

\section{ORCID}

Danilo Magno Marchiori (DiD http://orcid.org/0000-0002-7386-9706 Ricardo Gouveia Rodrigues (DD http://orcid.org/0000-0001-6382-5147

\section{References}

Agarwal, R., \& Prasad, J. (1999). Are individual differences germane to the acceptance of new information technologies? Decision Sciences, 30 (2), 361-391. doi:10.1111/j.1540-5915.1999.tb01614.x

Ahmad, U. N. U., Amin, S. M., \& Wan Ismail, W. K. (2014). Moderating effect of technostress inhibitors on the relationship between technostress creators and organisational commitment. Jurnal Teknologi (Sciences and Engineering), 67(1), 51-62. doi:10.11113/jt.v67.1932

Ayyagari, R., Grover, V., \& Purvis, R. (2011). Technostress: Technological antecedents and implications. MIS Quarterly, 35(4), 831-858. doi:10.1093/bja/aeq366

Baarspul, H. C., \& Wilderom, C. P. M. (2011). Do employees behave differently in public- vs private-sector organizations?: A state-of-theart review. Public Management Review, 13(7), 967-1002. doi:10.1080/ 14719037.2011.589614

Baltaci, S., \& Gokcay, D. (2016). Stress detection in human-computer interaction: Fusion of pupil dilation and facial temperature features. International Journal of Human-Computer Interaction, 32(12), 956966. doi:10.1080/10447318.2016.1220069

Barnett, J. H., \& Karson, M. J. (1989). Managers, values, and executive decisions: An exploration of the role of gender, career stage, 
organizational level, function, and the importance of ethics, relationships and results in managerial decision-making. Journal of Business Ethics, 8(10), 747-771. doi:10.1007/BF00383775

Brod, C. (1984). Technostress: The human cost of the computer revolution. Massachusetts: Addison Wesley Publishing Company.

Brooks, S., \& Califf, C. (2017). Social media-induced technostress: Its impact on the job performance of it professionals and the moderating role of job characteristics. Computer Networks, 114, 143-153. doi:10.1016/j.comnet.2016.08.020

Burton-Jones, A., \& Hubona, G. S. (2005). Individual differences and usage behavior: Revisiting a technology acceptance model assumption. ACM SIGMIS Database, 36(2), 58-77. doi:10.1145/1066149.1066155

Chua, S. L., Chen, D. T., \& Wong, A. F. L. (1999). Computer anxiety and its correlates: A meta-analysis. Computers in Human Behavior, 15(5), 609-623. doi:10.1016/S0747-5632(99)00039-4

Coffin, R. J., \& Macintyre, P. D. (1999). Motivational influences on computer-related affective states. Computers in Human Behaviour, 15(5), 549-569. doi:10.1016/S0747-5632(99)00036-9

Çoklar, A. N., \& Şahin, Y. L. (2011). Technostress levels of social network users based on ICTs in Turkey. European Journal of Social Science, 23 (2), 171-182.

Cooper, J. (2006). The digital divide: The special case of gender. Journal of Computer Assisted Learning, 22(5), 320-334. doi:10.1111/j.13652729.2006.00185.x

Czaja, S. J., \& Sharit, J. (1993). Stress reactions to computer-interactive tasks as a function of task structure and individual differences. International Journal of Human-Computer Interaction, 5(1), 1-22. doi:10.1080/10447319309526053

De Haes, S., Van Grembergen, W., \& Debreceny, R. S. (2013). COBIT 5 and enterprise governance of information technology: Building blocks and research opportunities. Journal of Information Systems, 27(1), 307-324. doi:10.2308/isys-50422

Elie-Dit-Cosaque, C., Pallud, J., \& Kalika, M. (2011). The influence of individual, contextual, and social factors on perceived behavioral control of information technology: A field theory approach. Journal of Management Information Systems, 28(3), 201-234. doi:10.2753/ MIS0742-1222280306

Fletcher, J. K. (2001). Disappearing acts: Gender, power, and relational practice at work. Cambridge, MA: Mit Press.

Fuglseth, A. M., \& Sørebø, Ø. (2014). The effects of technostress within the context of employee use of ICT. Computers in Human Behavior, 40, 161-170. doi:10.1016/j.chb.2014.07.040

Gabriel, S., \& Gardner, W. L. (1999). Are there "his" and "hers" types of interdependence? The implications of gender differences in collective versus relational interdependence for affect, behavior, and cognition. Journal of Personality and Social Psychology, 77(3), 642-655. doi:10.1037/0022-3514.77.3.642

Garicano, L., \& Heaton, P. (2010). Information technology, organization, and productivity in the public sector: Evidence from police departments. Journal of Labor Economics, 28(1), 167-201. doi:10.1086/649844

Hair, J. F., Babin, B., Money, A., \& Samouel, P. (2005). Fundamentos de métodos de pesquisa em administração. Porto Alegre: Bookman Companhia Ed.

He, J., \& Freeman, L. A. (2010). Are men more technology-oriented than women? The role of gender on the development of general computer self-efficacy of college students. Journal of Applied Computing and Information Technology, 21(2), 203-213.

Heinrich, K. T. (1991). Loving partnerships. The Journal of Higher Education, 62(5), 514-538. doi:10.1080/00221546.1991.11774150

Helsper, E. J., \& Eynon, R. (2010). Digital natives: Where is the evidence? British Educational Research Journal, 36(3), 503-520. doi:10.1080/ 01411920902989227

Holden, H., \& Rada, R. (2011). Understanding the influence of perceived usability and technology self-efficacy on teachers' technology acceptance. Journal of Research on Technology in Education, 43(4), 343-367. doi:10.1080/15391523.2011.10782576

Hsiao, K. L. (2017). Compulsive mobile application usage and technostress: The role of personality traits. Online Information Review, 41(2), 272-295. doi:10.1108/OIR-03-2016-0091
Hsiao, K. L., Shu, Y., \& Huang, T. C. (2017). Exploring the effect of compulsive social app usage on technostress and academic performance: Perspectives from personality traits. Telematics and Informatics, 34(2), 679-690. doi:10.1016/j.tele.2016.11.001

Huffman, A. H., Whetten, J., \& Huffman, W. H. (2013). Using technology in higher education: The influence of gender roles on technology self-efficacy. Computers in Human Behavior, 29(4), 1779-1786. doi:10.1016/j.chb.2013.02.012

Hung, W. H., Chen, K., \& Lin, C. P. (2014). Does the proactive personality mitigate the adverse effect of technostress on productivity in the mobile environment? Telematics and Informatics, 32(1), 143-157. doi:10.1016/j.tele.2014.06.002

Jena, R. K. (2015). Technostress in ICT enabled collaborative learning environment: An empirical study among Indian academician. Computers in Human Behavior, 51, 1116-1123. doi:10.1016/j. chb.2015.03.020

Jena, R. K., \& Mahanti, P. K. (2014). An Empirical study of Technostress among Indian Academicians. International Journal of Education and Learning, 3(2), 1-10. doi:10.14257/ijel.2014.3.2.01

Joiner, R., Gavin, J., Brosnan, M., Cromby, J., Gregory, H., Guiller, J., ... Moon, A. (2013). Comparing first and second generation digital natives' internet use, internet anxiety, and internet identification. Cyberpsychology, Behavior, and Social Networking, 16(7), 549-552. doi:10.1089/cyber.2012.0526

Joreskog, K. G., \& Goldberger, A. S. (1975). Estimation of a model with multiple indicators and multiple causes of a single latent variable. Journal of American Statistical Association, 70(351), 631-639.

Joshi, A., \& Roh, H. (2009). The role of context in work team diversity research: A meta-analytic review. Academy of Management Journal, 52 (3), 599-627. doi:10.5465/AMJ.2009.41331491

Korobili, S., Togia, A., \& Malliari, A. (2010). Computer anxiety and attitudes among undergraduate students in Greece. Computers in Human Behavior, 26(3), 399-405. doi:10.1016/j.chb.2009.11.011

Krishnan, S. (2017). Personality and espoused cultural differences in technostress creators. Computers in Human Behavior, 66, 154-167. doi:10.1016/j.chb.2016.09.039

Lau, D. C., \& Murnighan, J. K. (1998). Demographic diversity and faultlines: The compositional dynamics of organizational groups. Academy of Management Review, 23(2), 325-340. doi:10.5465/ AMR.1998.533229

Laumer, S., Maier, C., Eckhardt, A., \& Weitzel, T. (2016). User personality and resistance to mandatory information systems in organizations: A theoretical model and empirical test of dispositional resistance to change. Journal of Information Technology, 31(1), 6782. doi: $10.1057 /$ jit.2015.17

Lee, S. B., Lee, S. C., \& Suh, Y. H. (2016). Technostress from mobile communication and its impact on quality of life and productivity. Total Quality Management, 27(7), 775-790. doi:10.1080/ 14783363.2016.1187998

Maier, C. (2012). Personality within information systems research: A literature analysis. Ecis, 101. Retrieved from http://home.aisnet.org/ displaycommon.cfm? an $=1$ \&subarticlenbr $=346$

Maier, C. (2014). Technostress. Retrieved from https://d-nb.info/ $1066645345 / 34$

Maier, C., Laumer, S., \& Eckhardt, A. (2015). Information technology as daily stressor: Pinning down the causes of burnout. Journal of Business Economics, 85(4), 349-387. doi:10.1007/s11573-014-0759-8

Maier, C., Laumer, S., Eckhardt, A., \& Weitzel, T. (2015). Giving too much social support: Social overload on social networking sites. European Journal of Information Systems, 24(5), 447-464. doi:10.1057/ejis.2014.3

Maier, C., Laumer, S., Weinert, C., \& Weitzel, T. (2015). The effects of technostress and switching stress on discontinued use of social networking services: A study of Facebook use. Information Systems Journal, 25(3), 275-308. doi:10.1111/isj.12068

Marôco, J. (2014). Análise de equações estruturais: fundamentos teóricos, software \& aplicações. Lisboa, Portugal: ReportNumber.

Mikkelsen, A., Øgaard, T., Lindøe, P. H., \& Olsen, O. E. (2002). Job characteristics and computer anxiety in the production industry. 
Computers in Human Behavior, 18(3), 223-239. doi:10.1016/S07475632(01)00051-6

Morris, M. G., Venkatesh, V., \& Ackerman, P. L. (2005). Gender and age differences in employee decisions about new technology: An extension to the theory of planned behavior. IEEE Transactions on Engineering Management, 52(1), 69-84. doi:10.1109/TEM.2004.839967

Ng, T. W. H., \& Feldman, D. C. (2009). How broadly does education contribute to job performance? Personnel Psychology, 62(1), 89-134. doi:10.1111/j.1744-6570.2008.01130.x

Parayitam, S., Desai, K. J., Desai, M. S., \& Eason, M. K. (2010). Computer attitude as a moderator in the relationship between computer anxiety, satisfaction, and stress. Computers in Human Behavior, 26(3), 345352. doi:10.1016/j.chb.2009.11.005

Prensky, M. (2001). Digital natives, digital immigrants part 1 . On the Horizon, 9(5), 1-6.

Ragu-Nathan, T. S., Tarafdar, M., Ragu-Nathan, B. S., \& Tu, Q. (2008). The consequences of technostress for end users in organizations: Conceptual development and validation. Information Systems Research, 19(4), 417-433. doi:10.1287/isre.1070.0165

Rainey, H. G., \& Chun, Y. H. (2007). Public and private management compared. The Oxford handbook of public management. Oxford, UK: Oxford University Press. doi:10.1093/oxfordhb/9780199226443.003.0005

Riedl, R. (2012). On the biology of technostress: Literature review and research agenda. SIGMIS Database, 44(1), 18-55. doi:10.1145/ 2436239.2436242

Roberson, Q., Ryan, A. M., \& Ragins, B. R. (2017). The evolution and future of diversity at work. Journal of Applied Psychology, 102(3), 483499. doi:10.1037/apl0000161

Şahin, Y. L., \& Çoklar, A. N. (2009). Social networking users' views on technology and the determination of technostress levels. Procedia - Social and Behavioral Sciences, 1(1), 1437-1442. doi:10.1016/j.sbspro.2009.01.253

Saleem, H., Beaudry, A., \& Croteau, A. M. (2011). Antecedents of computer self-efficacy: A study of the role of personality traits and gender. Computers in Human Behavior, 27(5), 1922-1936. doi:10.1016/j.chb.2011.04.017

Schwark, J. D., Dolgov, I., Hor, D., \& Graves, W. (2013). Gender and personality trait measures impact degree of affect change in a hedonic computing paradigm. International Journal of Human-Computer Interaction, 29(5), 327-337. doi:10.1080/10447318.2012.711703

Scott, J. E., \& Walczak, S. (2009). Cognitive engagement with a multimedia ERP training tool: Assessing computer self-efficacy and technology acceptance. Information and Management, 46(4), 221-232. doi:10.1016/j.im.2008.10.003

Sellberg, C., \& Susi, T. (2014). Technostress in the office: A distributed cognition perspective on human-technology interaction. Cognition, Technology and Work, 16(2), 187-201. doi:10.1007/s10111-013-0256-9

Simon, F., \& Usunier, J. C. (2007). Cognitive, demographic, and situational determinants of service customer preference for personnel-incontact over self-service technology. International Journal of Research in Marketing, 24(2), 163-173. doi:10.1016/j.ijresmar.2006.11.004

Suh, A., \& Lee, J. (2017). Understanding teleworkers' technostress and its influence on job satisfaction. Internet Research, 27(1), 140-159. doi:10.1108/IntR-06-2015-0181

Tams, S., Hill, K., \& Thatcher, J. (2014). Journal of the association for information neuroIS - Alternative or complement to existing methods? Illustrating the holistic effects of neuroscience and self-reported data in the context of technostress research neuroIS - alternative or complement to ex. Journal of the Association for Information Systems, 15(October 2014), 723-753.

Tarafdar, M., Tu, Q., Ragu-Nathan, B., \& Ragu-Nathan, T. (2007). The impact of technostress on role stress and productivity. Journal of Management Information Systems, 24(1), 301-328. doi:10.2753/ MIS0742-1222240109

Tarafdar, M., Tu, Q., \& Ragu-Nathan, T. S. (2010). Impact of technostress on end-user satisfaction and performance. Journal of Management Information Systems, 27(3), 303-334. doi:10.2753/MIS0742-1222270311

Tarafdar, M., Tu, Q., Ragu-Nathan, T. S., \& Ragu-Nathan, B. S. (2011). Crossing to the dark side. Communications of the ACM, 54(9), 113. doi:10.1145/1995376.1995403
Van Knippenberg, D., De Dreu, C. K. W., \& Homan, A. C. (2004). Work group diversity and group performance: An integrative model and research agenda. Journal of Applied Psychology, 89(6), 1008-1022. doi:10.1037/0021-9010.89.6.1008

Venkatesh, V., Hall, M., Davis, G. B., Davis, F. D., Walton, S. M., \& Morris, M. G. (2003). User acceptance of information technology: Toward a unified. MIS Quarterly, 27(3), 425-478. doi:10.2307/ 30036540

Venkatesh, V., \& Morris, M. G. (2000). Why don't men ever stop to ask for directions? Gender, social influence, and their role in technology acceptance and usage behavior. MIS Quarterly, 24(1), 115. doi:10.2307/3250981

Venkatesh, V., Thong, J. Y. L., \& Xu, X. (2012). Consumer acceptance and use of information technology: Extending the unified theory of acceptance and use of technology. MIS Quarterly, 36(1), 157-178. doi:10.1111/j.1540-4560.1981.tb02627.x

Wahn, J. (2003). Sex differences in competitive and compliant unethical work behavior. Journal of Business and Psychology, 18(1), 121-128. doi:10.1023/A:1025039105839

Wang, K., Shu, Q., \& Tu, Q. (2008). Technostress under different organizational environments: An empirical investigation. Computers in Human Behavior, 24(6), 3002-3013. doi:10.1016/j.chb.2008.05.007

Weil, M. M., \& Rosen, L. D. (1997). Technostress: Coping with technology@work@home@play. New York, NY: John Wiley \& Sons.

Williams, K. Y., \& O’Reilly III, C. A. (1998). Demography and diversity in organizations : A review of 40 years of research. Research in Organizational Behavior, 20, 77-140.

Yan, Z., Guo, X., Lee, M. K. O., \& Vogel, D. R. (2013). A conceptual model of technology features and technostress in telemedicine communication. Information Technology \& People, 26(3), 283-297. doi:10.1108/ITP-04-2013-0071

Yeo, R. K., \& Gold, J. (2015). More than meets the eye: Working around technology in cross-boundary work contexts. Information Technology \& People, 28(3), 623-652. doi:10.1108/ITP-05-2013-0091

Young, J. P. (2000). Boy talk: Critical literacy and masculinities. Reading Research Quarterly, 35(3), 312-337. doi:10.1598/ Rrq.35.3.1

Zeithaml, V. A., Parasuraman, A., \& Malhotra, A. (2002). Service quality delivery through web sites: A critical review of extant knowledge. Journal of the Academy of Marketing Science, 30(4), 362-375. doi:10.1177/009207002236911

Zemke, R., Raines, C., \& Filipczak, B. (1999). Generations at work : Managing the clash of veterans, boomers, xers, and nexters in your workplace. AMACOM. Retrieved from https://dl.acm.org/citation. cfm?id $=1407588$

Zhou, J., Chourasia, A., \& Vanderheiden, G. (2017). Interface adaptation to novice older adults' mental models through concrete metaphors. International Journal of Human-Computer Interaction, 33(7), 592606. doi:10.1080/10447318.2016.1265827

\section{About the Authors}

Danilo Magno Marchiori is a Ph.D. candidate in Management at University of Beira Interior (Portugal) and MSc. in Management at FUCAPE Business School, Vitória/ES (Brazil). He is a research fellow in NECE-UBI (Núcleo de Estudos em Ciências Empresariais).

Emerson Wagner Mainardes is a Ph.D. in Management, Associate Professor at FUCAPE Business School, Vitória/ES, Brazil. He is a teacher and researcher in Management and Marketing. He is a research fellow in NECE (Núcleo de Estudos em Ciências Empresariais). Expertise: Innovation and Marketing.

Ricardo Gouveia Rodrigues is a Professor at University of Beira Interior and deputy director of the Research Centre NECE-UBI. He holds a Ph.D. in Business. His main research interests are Entrepreneurship and Marketing. He has over 40 international publications, participated in several projects and coordinated an international project on impact of Entrepreneurship Education. 